\title{
Economic performance assessment of two ROM ore milling circuit controllers
}

\author{
Donghui Wei, Ian K. Craig * \\ Department of Electrical, Electronic and Computer Engineering, University of Pretoria, Pretoria 0002, South Africa
}

\section{A R T I C L E I N F O}

\section{Article history:}

Received 23 October 2008

Accepted 28 February 2009

Available online xxxx

\section{Keywords:}

Mineral processing

Mineral economics

Particle size

Grinding

Flotation

Process control

\begin{abstract}
A B S T R A C T
Economic performance assessment of control systems is receiving increasing attention in both academia and industry. A relevant framework is proposed in Bauer and Craig (Bauer, M., Craig, I.K., 2008. Economic assessment of advanced process control - a survey and framework. Journal of Process Control 18 (1), 218 ) based on a comprehensive survey of the methods for economic analysis of advanced process control systems. The framework provides a formal procedure for the economic assessment of control systems. A practically motivated simulation study is used to cast the economic performance assessment of a nonlinear model predictive controller and three single-loop PID controllers for a run-of-mine milling circuit into this framework. Performance functions of the milling circuit, which dynamically relate the circuit process variables to monetary values, are developed based on a survey study on milling circuits and an in-depth literature study.
\end{abstract}

() 2009 Elsevier Ltd. All rights reserved.

\section{Introduction}

Maximising profit is often regarded as the primary objective of control systems used in the process industries, by improving the production capacity and satisfying the safety requirement and environmental regulations (Seborg et al., 2004). Economic performance assessment (EPA) is therefore crucial for control systems (Martin, 2005; Brisk, 2004) and is receiving increasing attention in both academia and industry (Friedmann, 2006). EPA usually includes the following steps:

- Developing performance functions of the process considered.

- Estimating probability density functions for process variables.

- Estimating optimal operating points and optimal overall performance.

- Estimating the performance improvement resulting from better control.

- Obtaining useful information on economic performance from historical data.

- Comparing the economic performance of controllers using a carefully designed experiment.

- Monitoring and optimising the real-time economic performance.

Methods for EPA of control systems used in the past decades were reviewed and incorporated into a framework (Bauer and Craig, 2008), as shown in Fig. 1. This framework consists of seven

\footnotetext{
* Corresponding author. Tel.: +27 12420 2172; fax: +27 123625000 .

E-mail address: icraig@postino.up.ac.za (I.K. Craig).
}

engineering steps and a managerial process, and will be used to assess the economic performance of two controllers of a run-of-mine (ROM) ore milling circuit. Steps 1-3 are undertaken before the controller is implemented (step 4), with the calculation of performance and success assessment (step 5) taking place immediately after implementation. Maintenance (step 6 ) and long-term assessment (step 7) will not be dealt with in this paper. Performance functions (PFs), which relate controlled variables to monetary values, play a crucial role in this framework and are used in steps 1, 3 and 5 (Bauer et al., 2007).

Grinding mill circuits are the most cost-intensive unit processes in the mineral processing industry, so their relevant economic performance analyses remain important (Wills and Napier-Munn, 2006; Hodouin et al., 2001). However, the performance is often not estimated satisfactorily (Hulbert, 2002; Lo et al., 1996; Radhakrishnan, 1999; Bourassa et al., 1995). The contribution of this paper is the EPA of three single-loop proportional-integral-derivative (PID) controllers and a nonlinear model predictive controller (NMPC) for a ROM milling circuit using the aforementioned framework. The PFs of the milling circuit are developed a priori based on a web-based survey and an in-depth literature investigation.

The organisation of this paper is as described below. The process description and model of the milling circuit considered are given in Section 2. In Section 3, the development of PFs of the circuit is shown, and the EPA of the circuit is conducted in Sections 4-8. The base case identification with single-loop PID controllers is discussed in Section 4 and the NMPC controller design is discussed in Section 5. The estimation of functional performance and initial economic assessment with NMPC is given in Section 6. The assumption for using the NMPC controller is made in Section 7. In 


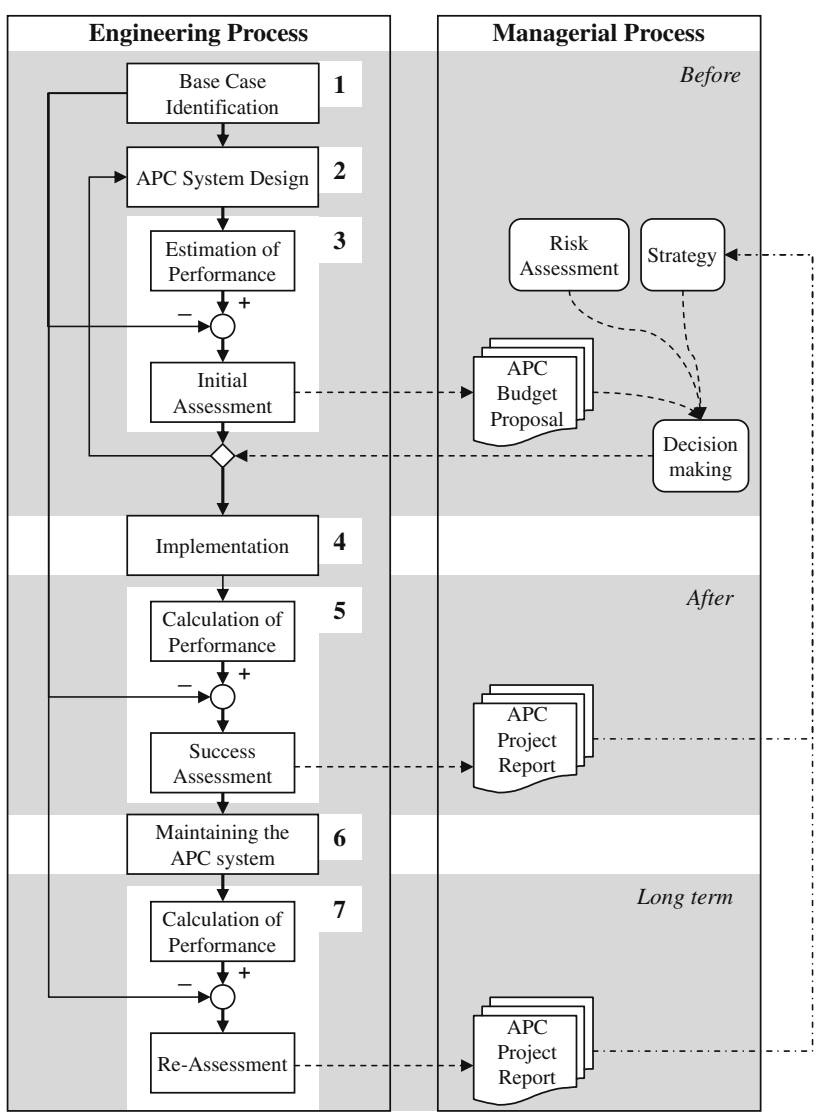

Fig. 1. The framework of EPA (Bauer and Craig, 2008).

Section 8 , the functional performance of the NMPC controller is investigated using a statistical experiment in which the NMPC and single-loop PID controllers are switched according to a completely randomised designed experiment; then an economic assessment is conducted to illustrate the economic performance improvement resulting from the NMPC control compared to single-loop PID controllers. Conclusions are drawn in Section 10.

\section{Process description and model of the milling circuit}

\subsection{Process description and process variables}

The considered ROM ore milling circuit is a closed one-stage circuit, comprising a semi-autogenous mill as shown in Fig. 2. It is assumed to process ore at approximately $100 \mathrm{t} / \mathrm{h}$ and to produce a

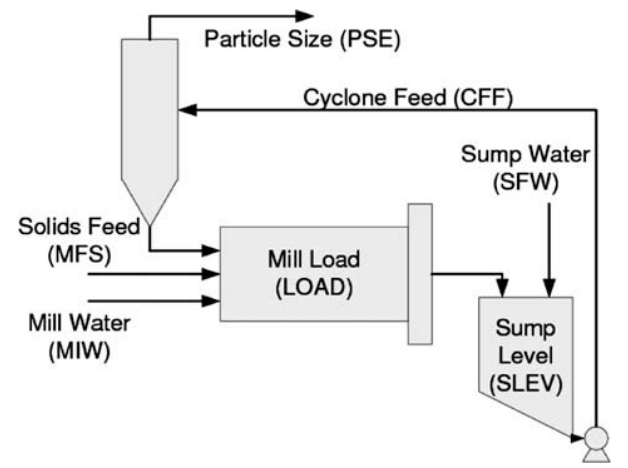

Fig. 2. The structure of the milling circuit (Coetzee et al., 2008).
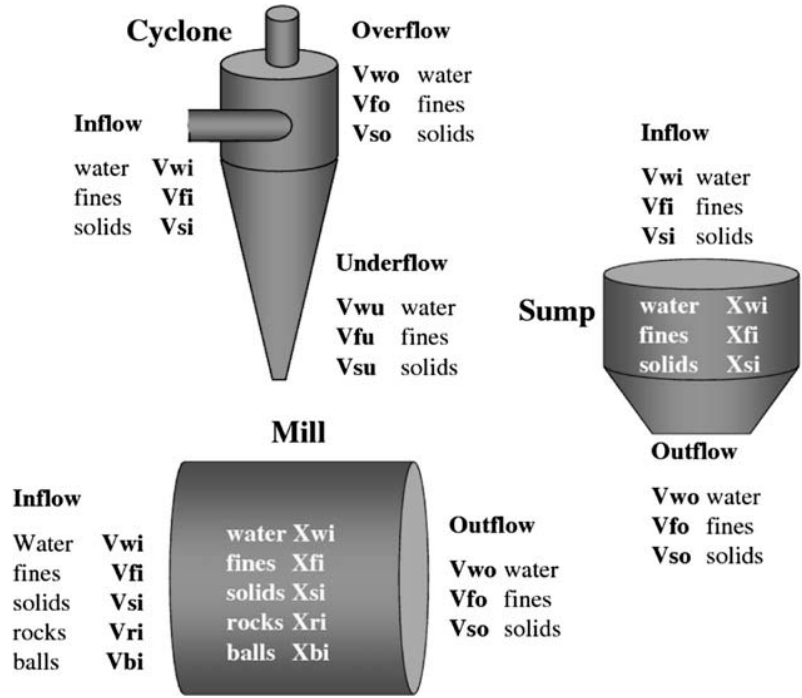

Fig. 3. The modules of the circuit model (Coetzee et al., 2008).

product of which approximately $80 \%$ passes $75 \mu \mathrm{m}$. The mill discharges slurry into a sump via an end-discharge grate. The slurry is diluted in the sump by water and pumped to a hydrocyclone. Lighter particles pass to the cyclone overflow, being the milling circuit product, and heavier particles pass to the underflow of the cyclone. The underflow of the cyclone, water and feed ore comprise the mill feed (Stanley, 1987).

The sump level (SLEV) and mill load (LOAD) are usually controlled, as they are open loop unstable. Considering the purpose of grinding mill circuits, the product particle size distribution (PSD) is also selected as a controlled variable. The manipulated variables are the feed rate of solids to the mill (MFS), the feed rate of water to the sump (SFW) and the cyclone feed flow rate (CFF). These manipulated and controlled variables are used frequently for milling circuit control (Wei and Craig, 2009). The control objective is firstly to stabilise the system and then to produce a product of which approximately $80 \%$ passes $75 \mu \mathrm{m}$ at an acceptable throughput.

\subsection{Model of the milling circuit}

The model used in Coetzee et al. (2009) is employed in this study. The relevant process variables and states are shown in Fig. 3. It comprises independent modules for the feeder, mill, sump and hydrocyclone. The separate modules can be linked to simulate various circuit configurations. The differential equations describing the nonlinear models are not shown here, for the sake of brevity. Instead, a brief description of how the process variables and states fit into the diagram in Fig. 2 is given. The circuit described in Fig. 2 has six inputs, five outputs and eight states.

Feeder: The feed ore comprises rock (that does not discharge from the mill), solids (out-of-specification but can discharge from the mill) and fines (in-specification material). The composition of the fine ore and rock is denoted by $\alpha_{f}$ and $\alpha_{r}$, respectively, as seen in Table 1.

Mill: The feed of the mill comprises three flow rates: the feed rate of fines $\left(V_{f i}\right)$, of solids $\left(V_{s i}\right)$ and of rocks $\left(V_{r i}\right)$ in $\mathrm{m}^{3} / \mathrm{h}$. There are two additional feeds: the flow rate of water to the mill $\left(V_{w i}\right)$ and the feed rate of balls to the mill $\left(V_{b i}\right)$. The mill has five states: the volume of water $\left(X_{m w}\right)$, solids $\left(X_{m s}\right)$, fines $\left(X_{m f}\right)$, rock $\left(X_{m r}\right)$ and balls $\left(X_{m b}\right)$ measured in $\mathrm{m}^{3}$. The LOAD is the summation of all the states of the mill. The mill has 14 parameters and the parameters characterising the ore hardness $\left(\eta_{f}, \phi_{r}, \phi_{b}\right)$ are shown in Table 2. 
Table 1

Operating point and constraints (OP means operating point).

\begin{tabular}{|c|c|c|c|c|}
\hline Variable & Min & Max & $\mathrm{OP}$ & Description \\
\hline$X_{m w}$ & 0 & 50 & 8.53 & The holdup of water in the mill $\left(\mathrm{m}^{3}\right)$ \\
\hline$X_{m s}$ & 0 & 50 & 9.47 & The holdup of ore in the mill $\left(\mathrm{m}^{3}\right)$ \\
\hline$X_{m f}$ & 0 & 50 & 3.54 & The holdup of fine ore in the mill $\left(\mathrm{m}^{3}\right)$ \\
\hline$X_{m r}$ & 0 & 50 & 20.25 & The holdup of rock in the mill $\left(\mathrm{m}^{3}\right)$ \\
\hline$X_{m b}$ & 0 & 20 & 6.75 & The holdup of balls in the mill $\left(\mathrm{m}^{3}\right)$ \\
\hline$X_{s w}$ & 0 & 10 & 3.95 & The holdup of water in the mill $\left(\mathrm{m}^{3}\right)$ \\
\hline$X_{s s}$ & 0 & 10 & 1.05 & The holdup of ore in the sump $\left(\mathrm{m}^{3}\right)$ \\
\hline$X_{s f}$ & 0 & 10 & 0.14 & The holdup of fine ore in the sump $\left(\mathrm{m}^{3}\right)$ \\
\hline MIW & 0 & 100 & 33.33 & The flow rate of water to the mill $\left(\mathrm{m}^{3} / \mathrm{h}\right)$ \\
\hline MFS & 0 & 200 & 100 & The flow rate of ore to the mill $(\mathrm{t} / \mathrm{h})$ \\
\hline$V_{b i}$ & 0 & 4 & 2 & The flow rate of balls to the mill $(\mathrm{t} / \mathrm{h})$ \\
\hline$\alpha_{\text {millspeed }}$ & 0.7 & 1.0 & 0.82 & The fraction of critical mill speed (dimensionless) \\
\hline CFF & 400 & 500 & 443 & The flow rate of water from the sump to the cyclone $\left(\mathrm{m}^{3} / \mathrm{h}\right)$ \\
\hline SFW & 0 & 400 & 267 & The flow rate of extra water to the sump $\left(\mathrm{m}^{3} / \mathrm{h}\right)$ \\
\hline LOAD & 30 & 50 & 45 & The total charge of the mill $\left(\mathrm{m}^{3}\right)$ \\
\hline SLEV & 2 & 9.5 & 5 & The level of the sump $\left(\mathrm{m}^{3}\right)$ \\
\hline Rheology & 0 & 1 & 0.51 & Describe the fluidity of the slurry in the mill (dimensionless) \\
\hline
\end{tabular}

Table 2

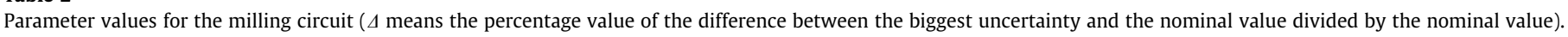

\begin{tabular}{|c|c|c|c|c|c|}
\hline Parameter & Nominal & Min & Max & $\% \Delta$ & Description \\
\hline$\alpha_{f}$ & 0.1 & 0.05 & 0.15 & 50 & Fraction of fines in the ore (dimensionless) \\
\hline$\alpha_{r}$ & 0.1 & 0.02 & 0.18 & 80 & Fraction of rock in the ore (dimensionless) \\
\hline$\eta_{f}$ & 28 & 5.6 & 50.4 & 80 & Power per ton of fines produced $(\mathrm{kWh} / \mathrm{t})$ \\
\hline$\phi_{r}$ & 69 & 55 & 83 & 20 & Rock abrasion factor $(\mathrm{kWh} / \mathrm{t})$ \\
\hline$\phi_{b}$ & 94 & 89 & 99 & 5 & Steel abrasion factor $(\mathrm{kWh} / \mathrm{t})$ \\
\hline$\varepsilon_{c}$ & 184 & 175 & 193 & 5 & Coarse split (dimensionless) \\
\hline$\alpha_{s u}$ & 0.16 & 0.15 & 0.17 & 5 & Fraction solids in underflow (dimensionless) \\
\hline
\end{tabular}

Sump: The sump feed consists of the mill discharge, including the flow rates of water $\left(V_{w i}\right)$, solids $\left(V_{s i}\right)$ and fines $\left(V_{f i}\right)$ given in $\mathrm{m}^{3} / \mathrm{h}$. The sump receives additional water $\left(V_{\text {wi-sump }}\right)$, i.e. SFW, to dilute the slurry in the sump. The sump discharge includes water $\left(V_{w o}\right)$, solids $\left(V_{s o}\right)$ and fines $\left(V_{f o}\right)$. The sump model has three states: the volume of water $\left(X_{s w}\right)$, solids $\left(X_{s s}\right)$ and fines $\left(X_{s f}\right)$ measured in $\mathrm{m}^{3}$. The SLEV is the summation of all the states of the sump.

Hydrocyclone: The hydrocyclone feed consists of water $\left(V_{w i}\right)$, solids $\left(V_{s i}\right)$ and fines $\left(V_{f i}\right)$ received from the sump. This feed is separated into an overflow and underflow stream with the product reporting to the overflow $\left(V_{w o}+V_{s o}+V_{f o}\right)$ and the out-of-specification material $\left(V_{w u}+V_{s u}+V_{f u}\right)$ reporting to the underflow. The split is not perfect and both the overflow and underflow contain unwanted material. The cyclone has six parameters overall. The parameters describing the classification efficiency $\left(\varepsilon_{c}\right.$ and $\left.\alpha_{s u}\right)$ are shown in Table 2.

\subsection{Operating point and constraints}

In order to make the simulation of the process and control system as realistic as possible, a suitable operating point and process variable and parameter constraints are defined. The operating point and all the constraints on process states are given in Table 1. Uncertainties in the parameters of interest are shown in Table 2.

\subsection{The economic concerns of milling circuit control systems}

The economic objectives of milling circuits are to produce a product, at a reasonable throughput, from which good recovery can be achieved in the downstream processes, and to reduce operating cost. The objectives can usually be classified into two categories, i.e. increasing benefits and decreasing costs. Control systems can contribute to realizing these objectives. A survey study on milling circuits was conducted to determine the benefits factors (Wei and Craig, 2009).
In the survey the respondents were asked to indicate three main benefits resulting from a process control system; the results are given in Fig. 4. Process stability improvement was considered as the primary advantage (71\%). Throughput increase and energy consumption reduction are also considered as main benefits (54\% and $50 \%$, respectively). These results are similar to those reported in Samskog et al. (1996) for grinding mills and to what was reported in Bauer and Craig (2008) for the process industries as a whole. Bourassa et al. (1995) consider stability improvement and throughput increase to be important, but not energy savings. The reduction of energy consumption is nevertheless declared to be a primary benefit of process control in van Dyk et al. (2000) and Galán et al. (2002) because of the fast increasing mineral processing costs in recent years; throughput improvement is also considered important in these two works. Lo et al. (1996) state that benefits resulting from process control mainly include throughput increase and power consumption reduction, and stability improvements are not regarded as crucial. Throughput increase is regarded as a benefit by Herbst et al. (1988a), Herbst et al. (1989). However, Hulbert (1989) states that good control of grinding mill circuits realizes relatively small benefits compared to those from subsequent process optimization.

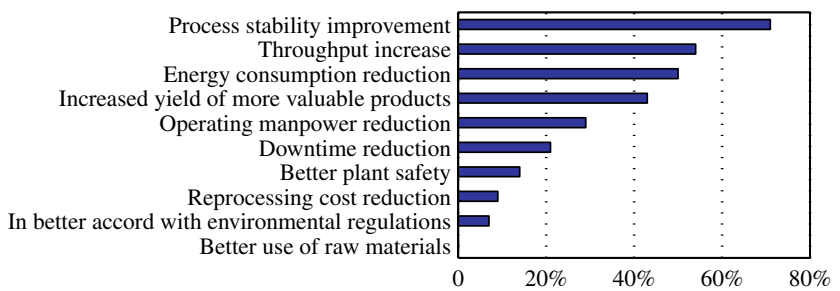

Fig. 4. Benefit types due to a process control system. 
The economic performance of milling control systems is often not satisfactorily estimated (Hulbert, 1989, 2002; Lo et al., 1996; Radhakrishnan, 1999; Bourassa et al., 1995) despite the primary objective, when installing a control system, being to gain as much monetary benefit as possible. This fact is confirmed by the survey results reported in Wei and Craig (2009). The reason may be that the relationships between the controlled variables in the grinding and flotation circuits and the economic objectives of a mineral processing plant are difficult to obtain (Sosa-Blanco et al., 2000). The objectives are often broken down into particle size reduction, throughput increase, better recovery, etc. The optimization of grinding and flotation circuits individually does not necessarily result in optimal performance of the overall system. The operation of the milling circuits has a great influence on the economic performance of a mineral processing plant, but investigating the economics of grinding circuits alone cannot yield a satisfactory result, as the major economic influence of the milling operation occurs in the downstream processes (Hodouin et al., 2001). A unifying study, considering the grinding and flotation circuits together, is employed in this paper for the economic assessment of the milling circuit being considered.

\section{Performance functions of the milling circuit}

PFs play a key role when the framework proposed in Bauer and Craig (2008) is used for the EPA of control systems. PFs are used in steps 1,4 and 7 of the framework. Without the PFs, the identification of the economic performance of a base case, the estimation of the economic performance of the new controller and the calculation of performance after the new controller is implemented cannot be achieved. In this section, the PFs of the milling circuit considered are developed.

\subsection{Introduction to milling circuit PFs}

In many cases, the variation of a process variable can be related to a monetary value. A performance function defines either profit or cost when the process variable fluctuates around the optimal operating point (Stout and Cline, 1976; Bawden, 1993; Latour, 1996; Zhou, 2002). There are several frequently used PFs, such as the quadratic, CLIFFTENT and linear-constraint ones discussed in Bauer et al. (2007). The derivation of PFs requires comprehensive and in-depth knowledge of the process. A methodology for developing PFs is difficult to establish, as economic modelling depends on specific characteristics of the processes under study (Williams and Rameshi, 1998).

PFs of the milling circuit controlled variables (PSD, LOAD and SLEV) will be derived in the sequel. The economic consequences can be denoted by either additional profit $(\Delta P)$ or cost $(\Delta C)$ incurred for a given scenario when compared to an optimal operating condition. In this paper each controlled variable will be related to $(\Delta P-\Delta C)$. Note that the PFs are independent of the control technology used. They rather depend on the system dynamics, process economics, operational specifications and market conditions.

Generally for a PF there are two possible options, i.e. using real plant data or using sanitised plant data expressed as percentage values. Real plant data are often difficult to obtain as they are usually confidential. It holds in Zhou and Forbes (2003) where only brief results are given and detailed information is protected. Hence, taking the first option tends not to be practical for academic research, but it is ideal for an internal evaluation of an industrial plant. Alternatively, the second option can be used, where the percentage values of $\Delta C / \Delta P$ are divided by a nominal value such as the average operating cost of the process for a given period. This is the case in Oosthuizen et al. (2004), where the PFs are expressed as percentage values of additional costs divided by the typical operating cost for a tap of an electric arc furnace. The use of percentage values has the advantage that sensitive production data can be protected and are consequently easier to obtain.

\subsection{Assumptions used for PF development}

Owing to the highly complex nature of the economic relations in most processes, assumptions usually need to be made in order to facilitate the development of PFs (Oosthuizen et al., 2004; Zhou and Forbes, 2003). The assumptions are:

(1) The economic impact of the controlled variables is independent of each other (see Wei et al. (2007) for instances where this is not the case).

(2) When the grind fineness varies, the mineral recoveries will differ.

(3) When the SLEV or LOAD violates predetermined limits, the grinding system will be shut down and then some compensative action will need to be taken in order to restore normal operation some time after the malfunction.

(4) Slightly better or worse grinding does not significantly change the operating cost of the milling circuit. The basis of this assumption is that the change in the operating cost may be very small compared to the change in the value of recovered mineral.

(5) The product of the milling circuits is assumed to be the feed to the flotation circuit.

(6) The head grade of the feed ore and throughput rate of the milling circuit are assumed to be constant over the period of interest.

(7) As far as the milling circuit product PSD vs flotation recovery relation is concerned, the operating cost of the flotation circuit is assumed to remain constant.

\subsection{Development of PFs}

In this section, the development of PFs for the milling circuit is discussed. For each controlled variable of interest, the information used to establish a PF is given first and then the derived PF is shown. The information required is obtained mainly from an indepth literature study and a survey (Wei and Craig, 2009). Some results of the survey are incorporated into the analysis below.

\subsection{1. $P F$ for the PSD}

A literature survey was conducted on the steady-state relationship between the ore PSD of a grinding mill circuit product and the recovery of the downstream flotation circuit. The relation is also referred to as the recovery vs grind relation for the sequel of this paper. The primary hindrance to establishing this relation lies in the difficulty in predicting the mineral PSD for the feed of flotation circuits from the ore PSD of the milling circuit product (King, 1979; Herbst et al., 1988b; Sosa-Blanco et al., 1999). The consistency of the shapes of the curves describing this relation, recovery vs ore PSD, is illustrated in Grant et al. (1991), Bascur (1991), Bazin et al. (1994a,b, 1995), Edwards and Vien (1999) and Sosa-Blanco et al. (1999), and will be reviewed next.

The consistency of the recovery vs grind relation arises from two consistencies, i.e. the consistency of the relation between the recovery and the particle size of the feed to the flotation circuit and the consistency between the mineral PSD and ore PSD of the milling circuits product. Research into the relation between recovery and particle size has remained important in the mineral processing industry and can be classified into two stages. The relation between the recovery and particle size fractions in the flo- 
tation circuits is investigated in the first stage. In the second stage, the relation between the recovery in the flotation circuits and the ore PSD of the milling product is considered.

A popular method to obtain the relation between the recovery and particle size fractions is to divide the feed to the flotation circuit into different size fractions, e.g., $10-20 \mu \mathrm{m}$ and 35-52 $\mu \mathrm{m}$ and so on, then to record the average size of each fraction, to perform flotation on each fraction, and then to record the recovery for each fraction. Consequently, for each fraction, a point associated with an average particle size and the relevant recovery is established. The overall relation between the recovery and particle size fraction can then be formed based on all these points. The types of the curves used to formulate the relations, in both real plants and laboratory batch tests, have been regarded as highly consistent in a number of studies (Trahar, 1981; Trahar and Warren, 1976; Lynch and Bush, 1977; Lynch, 1981; Jones et al., 1991; Bascur, 1991; Feng and Aldrich, 1999), as shown, e.g., in Fig. 5. The ore particles can be roughly classified into three sections, namely those for fine particles, intermediate particles and coarse particles (Trahar, 1981). The ore may contain various minerals and not all minerals show maximum recovery in the same size ranges. The slower flotation of fine particles results from a lower rate of attachment of particles to bubbles. Fine particles have a lower rate of collision with bubbles and a lower momentum, which reduces the probability of adhesion and subsequent flotation (Trahar and Warren, 1976). The shape of the curve is regarded as reasonably independent of moderate variations in particle size distribution, valuable mineral content and pulp density (Trahar, 1981). Two main mechanisms can account for the behaviour of coarse particles. The first is that the degree of hydrophobicity needed to facilitate a high level of floatability increases with the increase in particle size. The second is that rapid collector consumption by the fine particles causes less surface coverage of the coarse particles, which consequently are less floatable.

In the second stage, the relationship between the recovery and the size distribution is considered. Note that in this context the Rosin-Rammler distribution is used to reflect the particle size distributions, describing the percentage of ore passing a given size. The effect of the size distribution on the flotation recovery has also been investigated and it has been discovered that the types of relations also remain consistent for various minerals in both industrial flotation circuits and laboratory tests (Grant et al., 1991; Bazin et al., 1994b, 1995; Edwards and Vien, 1999; Sosa-Blanco et al., 1999). The recovery vs size distribution relation is derived from the recovery vs size fraction relation and a transformation from mineral PSD to the probabilities that mineral falls into various size fractions. The results for the first stage and those for the second stage are inherently consistent owing to this transformation.

The relation between ore PSD and mineral PSD is also found to be consistent, for a given mineral processing plant, as shown in King (1979), Grant et al. (1991), Bazin et al. (1994a, 1995) and Sosa-Blanco et al. (1999).

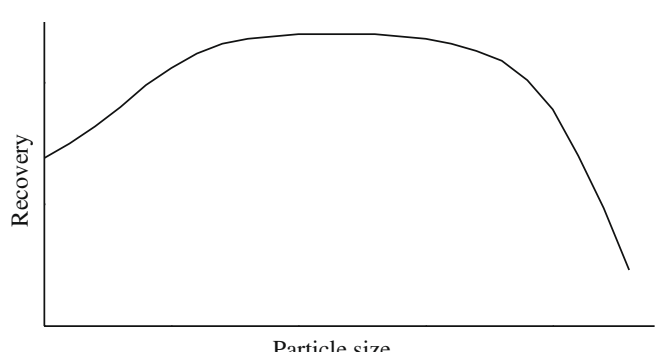

Fig. 5. Recovery vs size fraction relation (from Lynch and Bush (1977)).

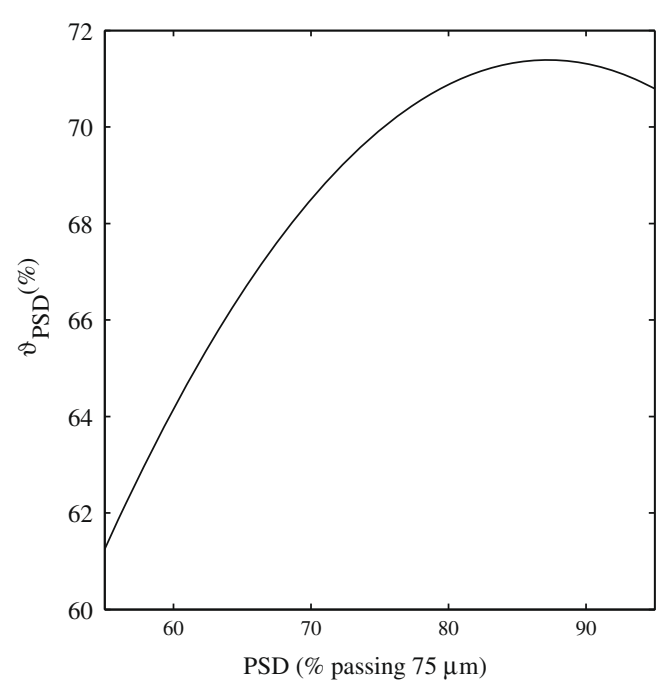

Fig. 6. Performance function (recovery) of the ore PSD of the milling circuit product (adapted from Fig. 7 in Edwards and Vien (1999)).

The consistency of the recovery vs PSD relation for a given mineral processing plant is therefore established based on the consistency of the recovery vs mineral size relation and the consistency of the ore PSD vs mineral PSD relation. A typical curve for the recovery vs ore PSD relation is a quadratic function. This consistency has a significant influence on the economic performance assessment of milling circuits, since the economic impact of the downstream flotation circuit is included without additional examination of the flotation circuit. The relation can be used as a performance function in the context of EPA of milling circuit controllers.

When the recovery vs milling circuit product's PSD relation is determined, it is relatively straightforward to calculate the value of the mineral recovered over a given period using Eq. (1):

Mineral value $[\$]=($ throughput rate $[\mathrm{t} / \mathrm{h}])$

$$
\begin{aligned}
& \times(\text { time period }[\mathrm{h}]) \times(\text { head grade }[\mathrm{g} / \mathrm{t}]) \\
& \times(\text { recovery }[\%]) \times(\text { mineral price }[\$ / g])
\end{aligned}
$$

In the milling circuit being considered, the performance function for the PSD is derived as:

$\vartheta\left(y_{1}\right)=a y_{1}^{2}+b y_{1}+c$

where $a=-0.009776, b=1.705$ and $c=-2.955$. $y_{1}$ refers to the PSD. The PF is shown in Fig. 6. The maximum recovery is $71.4 \%$ and the relevant operating point is $87.2 \%$ passing $75 \mu \mathrm{m}$ (Edwards and Vien, 1999). However, in what follows, $80 \%$ is used as the setpoint for the PSD, not $87.2 \%$. There are several reasons for this selection. The PSD setpoint is usually selected based on a trade-off that too fine a grind maximises the mineral liberation at the expense of throughput and high energy cost, whereas too coarse a grind decreases concentrate grade because of the presence of midlings (Wills and Napier-Munn, 2006; Hodouin et al., 2001). Maximising the net revenue of the recovered mineral tends to decrease metallurgical performance and increase the loss of valuable minerals (low recovery) to the plant tailings, which has ethical implications for resource conservation and environmental concerns (Sosa-Blanco et al., 2000). Theoretically, the PSD setpoint should be selected based on the relation between recovery and grinding circuit product PSD. However practically, the narrowest PSD in the size range of maximum recovery is obtained at the design or tuning stage of the grinding circuit, and the operation is controlled at a single target (Hodouin et al., 2001). 


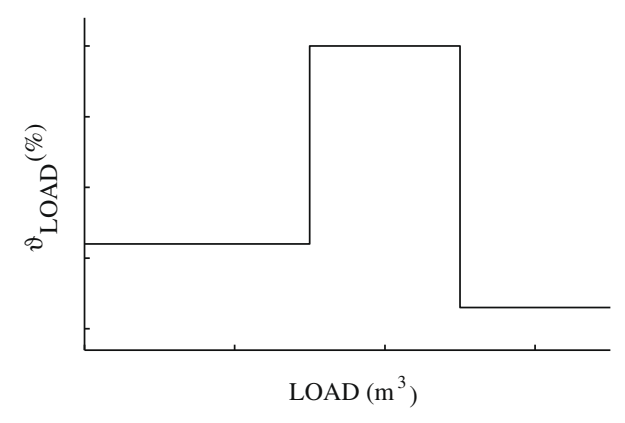

Fig. 7. Performance function of the LOAD.

\subsubsection{PF for the $L O A D$}

The LOAD is controlled within a range to ensure the stability of the system. When the LOAD is slightly higher or lower than the nominal value, some compensative action will be taken. Performing such action is routine for the controller and does not cause additional cost/benefit. When the mill load exceeds predetermined upper or lower limits, the operation needs to be stopped and compensative action will be conducted in order to restore routine operation (Wei and Craig, 2009).

The PF of the LOAD can therefore be described as a piece-wise function consisting of three ranges (see Fig. 7). The middle range is the one within which the LOAD is expected to stay. The other two ranges relate to where the LOAD exceeds an upper/lower limit. In the middle range, the economic impact will be zero since the operation is within specification and there is no additional cost and profit. The PF of the LOAD is unsymmetrical, as the compensative actions for a too low LOAD and a too high LOAD are not necessarily the same and accordingly may cause different expenses. Note that the setpoint of the LOAD is often changed dynamically to maximise the power drawn from the mill motor, as optimum grinding is often regarded to take place when this happens in the middle range (Craig et al., 1992). Such an optimiser will not be considered in this study. Because of the relatively simple dynamics of the LOAD, it can usually be controlled well and the possibility of violating the constraints is pretty small. So it is not the focus of this paper. The same argument applies to the SLEV as well.

\subsubsection{PF for the SLEV}

The specification for the SLEV is also to stay within a selected range. When the SLEV exceeds a predetermined upper or lower limit, compensative action will be taken, which will have some economic consequences (Wei and Craig, 2009).

The PF of the SLEV can also be described by a piece-wise function consisting of three ranges; see Fig. 8 . The middle range is the one in which the SLEV is expected to stay. The other two ranges are those in which the SLEV exceeds the upper/lower limit. In the middle range, the economic impact will be zero since the operation is

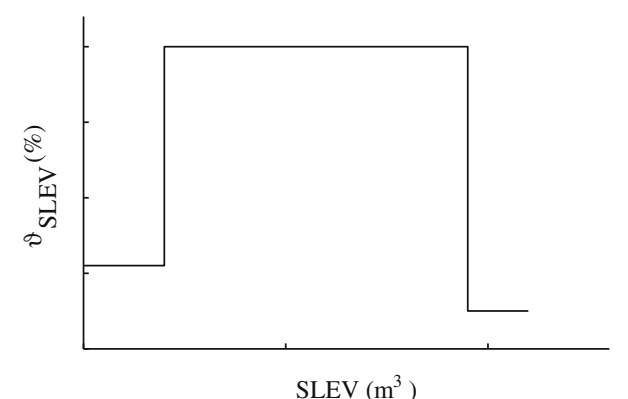

Fig. 8. Performance function of the SLEV.
Table 3

Notation of variables used in expressing performance.

\begin{tabular}{ll}
\hline Variable & Description \\
\hline$y_{1}$ & PSD \\
$y_{2}$ & LOAD \\
$y_{3}$ & SLEV \\
$\Psi$ & The overall system performance for a given period \\
$\Psi_{y_{i}}$ & The economic performance with reference to $y_{i}$ \\
$v\left(y_{i}\right)$ & Performance function for $y_{i}$ \\
$f\left(y_{i}\right)$ & Probability density function of $y_{i}$ \\
$\Delta C\left(y_{i}\right)$ & Additional cost for $y_{i}$ compared to the base level \\
$\Delta C_{m}\left(y_{i}\right)$ & Additional milling circuit cost for $y_{i}$ compared to the base level \\
$\Delta C_{f}\left(y_{i}\right)$ & Additional flotation circuit cost for $y_{i}$ compared to the base level \\
$\Delta P\left(y_{i}\right)$ & Additional profit for $y_{i}$ compared to the base level \\
$\Delta P_{m}\left(y_{i}\right)$ & Additional milling circuit profit for $y_{i}$ compared to the base level \\
$\Delta P_{f}\left(y_{i}\right)$ & Additional flotation circuit profit for $y_{i}$ compared to the base level \\
\hline
\end{tabular}

within specification and there is no additional cost and profit. The PF of the SLEV is unsymmetrical, as the compensative action for too low a SLEV and too high a SLEV are not necessarily the same and accordingly may cause different expenses. In this work the SLEV is controlled at a fixed setpoint for comparative purposes, but as the sump acts as a buffer, it is only required to be range-bound (Hulbert et al., 1990).

\subsection{Overall economic performance of the circuit}

The model used to describe the overall economic performance of the milling circuit is discussed in this section. As far as the performance related to a controlled variable is concerned, it is estimated by integrating the product of the relevant performance function and probability density function. This method is increasingly used (Latour, 1996, 2006; Zhou and Forbes, 2003; Mascio and Barton, 2001; Bauer and Craig, 2008) because of the increased accuracy in estimating the economic performance compared to the methods used in e.g., Martin et al. (1991), Martin (2004), Muske and Finegan (2002). The notation used to indicate the overall economic performance of the system is given in Table 3 . The overall performance of the circuit is given in Eq. (3).

$\Psi=\Psi_{y_{1}}+\Psi_{y_{2}}+\Psi_{y_{3}}$

where

$\Psi_{y_{i}}=\int_{-\infty}^{\infty} v\left(y_{i}\right) f\left(y_{i}\right) d y_{i}$

where for each considered controlled variable

$$
\begin{aligned}
v\left(y_{i}\right) & =\Delta P\left(y_{i}\right)-\Delta C_{\left(y_{i}\right)} \\
& =\Delta P_{m}\left(y_{i}\right)+\Delta P_{f}\left(y_{i}\right)-\Delta C_{m}\left(y_{i}\right)-\Delta C_{f}\left(y_{i}\right)
\end{aligned}
$$

Note that the integral, as described in Eq. (4), usually corresponds to the data collected over a period, either from a real plant or a simulation. The probability density functions $\left(f\left(y_{i}\right)\right)$ can be derived from the operating data of controlled variables. The PF for each controlled variable $\left(v\left(y_{i}\right)\right)$ is described in Section 3.3.

\section{Framework step 1: base case identification}

The first step when considering a control upgrade project is to analyse the performance of the current system, often referred to as the base case. This step needs an in-depth understanding of the process being considered, such as the process dynamics, economics, operating conditions, operating constraints, etc. It also needs careful selection of the operating data, which should reflect the typical operation of the process considered.

The base case in this work is the scenario where the milling circuit is controlled by three single-loop PID controllers. PID control is used here, as most milling circuits in industry are controlled this 
way (Wei and Craig, 2009). The controller design, relevant functional performance and economic performance are then discussed in the following.

\subsection{PID controllers design}

Single-loop PID controllers used in Coetzee et al. (2008) are used in the base case. Linear step response models for the circuit are obtained from the nonlinear model described in Section 2.2. The three PID controllers control the PSD-CFF, LOAD-MFS and SLEV-SFW loops. The PID controllers were tuned using the Skogestad Internal Model Control design procedure described in Skogestad (2003). This procedure has two steps, firstly obtaining a first- or second-order plus delay model using a proposed 'half-rule' and then deriving PID controller settings using proposed analytical rules. The PID controllers designed using this procedure generally yield better performance in terms of disturbance rejection and setpoint tracking compared to the traditional PID-tuning methods (Skogestad, 2003). Specifically, disturbance rejection is improved significantly for integrating processes, which is applicable to this paper, as the LOAD and SLEV are integrators for the milling circuit examined.

\subsection{Functional performance of the PID controllers}

The milling circuit controlled by the PID controllers is simulated using a typical disturbance scenario. The simulation period of $24 \mathrm{~h}$ is selected in order to give the system sufficient time to respond to disturbances. In the simulation, the process differs from the nominal model used for the controller design, as the parameters of the milling circuit are uncertain. The parameters shown in Table 2 are used, modelled as uniform distributions within the constraints. The most significant uncertainties for the ROM milling circuit are the rock hardness and the rock fraction in the mill feed ore. Both of them are employed in order to make the simulation more realistic. The ore hardness is increased by $80 \%$ at time 200 min until the end of simulation and the rock fraction is increased by $90 \%$ at time $800 \mathrm{~min}$ until the end of simulation. The disturbance sizes are selected based on the investigation of the disturbance scenarios used in for example Hulbert et al. (1990), Yahmedi et al. (1998) and Coetzee et al. (2009). Note that both the hardness and rock fraction disturbances have two components. One is the base level, or alternatively speaking the average level, and the other is a random var-
Table 4

Statistical data of controlled variables for the PID controllers.

\begin{tabular}{lll}
\hline Controlled variable & $\mu_{y_{i}}$ & $\sigma_{y_{i}}$ \\
\hline PSD $(\%<75 \mu \mathrm{m})$ & 75.05 & 3.94 \\
LOAD $(\%$ full) & 45.00 & 0.04 \\
SLEV $(\%$ full) & 49.99 & 0.17 \\
\hline
\end{tabular}

iation around the base level. The disturbances are large but not uncommon in practice.

The simulation results are shown in Fig. 9. It can be seen that the LOAD and SLEV are controlled well, as the dynamics associated with them are relatively simple. From time $200 \mathrm{~min}$ the PSD drops owing to the increase in ore hardness. After time 800 min the PSD slowly drifts back to setpoint as the increase in ore hardness is now countered by the increase in rock fraction. The PSD-CFF controller is not able to maintain the PSD at setpoint as CFF is saturated at its upper limit of $500 \mathrm{~m}^{3} / \mathrm{h}$ from just after time $200 \mathrm{~min}$.

The time series of the controlled variables are assumed to follow Gaussian distributions if generated by a linear source. Skewness and kurtosis tests confirmed that the time series of the controlled variables reported on in this paper follow Gaussian distributions (Tabachnick and Fidell, 2001). Because most process control loops are approximately linear within a specific operating region, the time trends of a controlled variable are often regarded as Gaussian (Bauer et al., 2007). Furthermore, the non-Gaussianity of a time series in a control loop is often an indication that the loop might be performing poorly (Choudhury et al., 2004; Thornhill and Horch, 2007). When the $\mu_{y_{i}}$ and $\sigma_{y_{i}}$ are used to represent the mean and standard deviation of the time series of $y_{i}$, the probability density function (PDF) can be depicted as follows:

$f\left(y_{i}\right)=\frac{1}{\sqrt{2 \pi} \sigma_{y_{i}}} \exp \left\{-\frac{\left(y_{i}-\mu_{y_{i}}\right)^{2}}{2 \sigma_{y_{i}}^{2}}\right\}$

The PDFs of the controlled variables are obtained in terms of average values and standard deviations, as shown in Table 4.

\subsection{Economic performance of the base case}

The preferred way to indicate economic performance is by integrating the product of a PF and PDF of a time series of a process variable over a period of interest (Zhou, 2002; Wei et al., 2007; Oosthuizen et al., 2004), as described in Section 3.4.
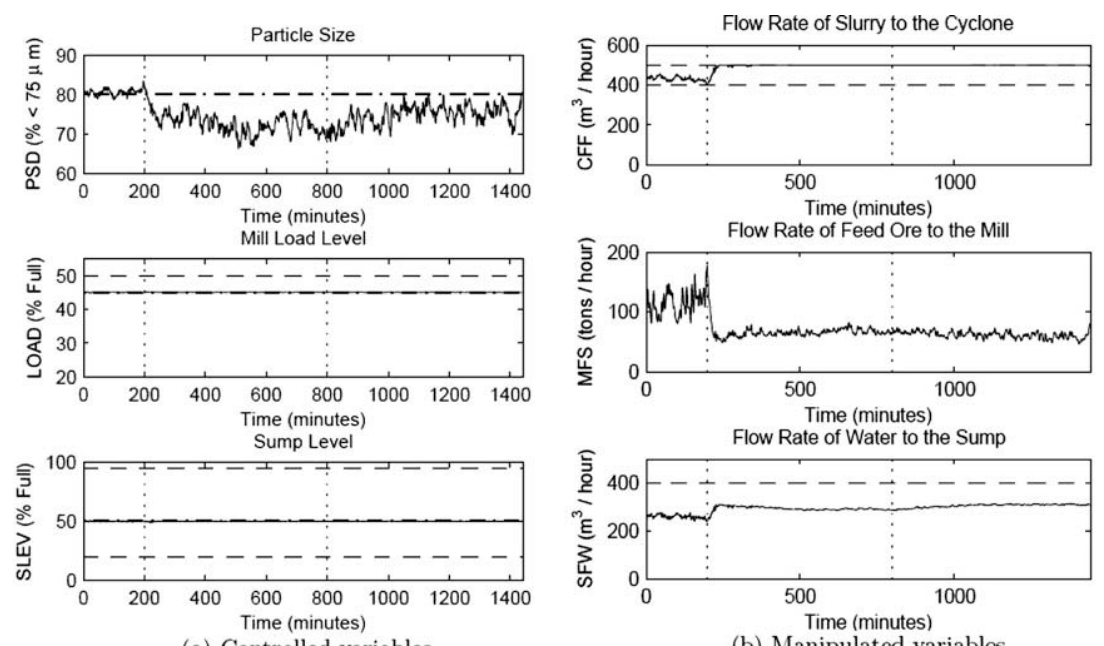

(a) Controlled variables

(b) Manipulated variables

Fig. 9. Controlled and manipulated variables of one day operation for the PID controllers. 
Both the LOAD and SLEV are controlled well and do not deviate from the constraints and thus the relevant economic impact is null. The fluctuation of the PSD around the setpoint causes a fluctuation in recovery which is economically significant. The overall economic performance index (EPI) is therefore equal to the EPI associated with the PSD, which is

$$
\begin{aligned}
\Psi_{y_{1}} & =\int_{-\infty}^{\infty} v\left(y_{1}\right) f\left(y_{1}\right) d y_{1} \\
& =\int_{-\infty}^{\infty}\left(\frac{1}{\sqrt{2 \pi} \sigma_{y_{1}}} \exp \left\{-\frac{\left(y_{1}-\mu_{y_{1}}\right)^{2}}{2 \sigma_{y_{1}}^{2}}\right\}\right)\left(a y_{1}^{2}+b y_{1}+c\right) d y_{1}
\end{aligned}
$$

where $a=-0.009776, b=1.705$ and $c=-2.955$.

It can be seen from the PF of the PSD shown in Fig. 6 that the optimal operating point for the PSD is $87.2 \%$ and the relevant optimal recovery is $71.4 \%$. The economic performance of the base case is derived by substituting the values given in Table 4 into Eq. (7) over the simulation period; the average base case recovery of the downstream flotation circuit is $69.61 \%$. For the purpose of this study, if the product of the throughput rate, time period, head grade and price of the recovered mineral is noted as $k$, then the recovered mineral value is

$\begin{aligned} \text { Value }= & (\text { throughput rate }) \times(\text { time period }) \times(\text { head grade }) \\ & \times(\text { recovery }) \times(\text { mineral price })=\text { recovery } \times k\end{aligned}$

according to Eq. (1). The value of recovered mineral of the base case is therefore $(69.61 \mathrm{k}) \%$. For any given circuit, the actual mineral value can be obtained by substituting the values of throughput rate, time period, mineral price and head grade into Eq. (8).

\subsection{Performance bound}

The reduction of the variation of controlled variables can often produce economic improvement as long as the performance functions are not linear and unconstrained. However, there is a theoretical limit to the reduction in the variance for any given process. Minimum variance control is aimed at controlling at this theoretically lower bound and has been intensively researched (Harris et al., 1996; Qin, 1998; Huang and Shah, 1999; Huang, 2002; Huang et al., 2005; Jelali, 2006). For a given operating point, the economic performance bound corresponds to the theoretical minimum variance, which often cannot be realized physically but can be used as an indication of by how much the variance of the controlled variables can be reduced.

The minimum variance based performance index is defined as:

$\eta=\sigma_{m v}^{2} / \sigma_{y}^{2}$

where $\sigma_{m v}^{2}$ is the minimum variance of a process variable and $\sigma_{y}^{2}$ is the variance of the process variable based on the data collected over a period of interest. The range of $\eta$ is between 0 and 1 . When $\eta$ is close to 1 , the variance of the controlled variable considered is already near the theoretical minimum and there is not much room to improve the controlled variable performance from the viewpoint of variance reduction. When $\eta$ is close to 0 , the controlled variable variance can be reduced significantly.

The minimum variance can be obtained from process data and a process model. The data generated in Section 4.2 and the linearised transfer function model of the circuit are used for the calculation of the minimum variance. Since the focus of economic performance is mainly on the PSD here, $\eta$ of only the PSD is derived. Here, the minimum variance is calculated using the filtering and correlation analysis algorithm given in Huang and Shah (1999). The obtained $\eta$ is 0.01 . Considering the standard deviation of the PSD of the base case is 3.94, the minimum variance for the PSD is obtained as 0.15

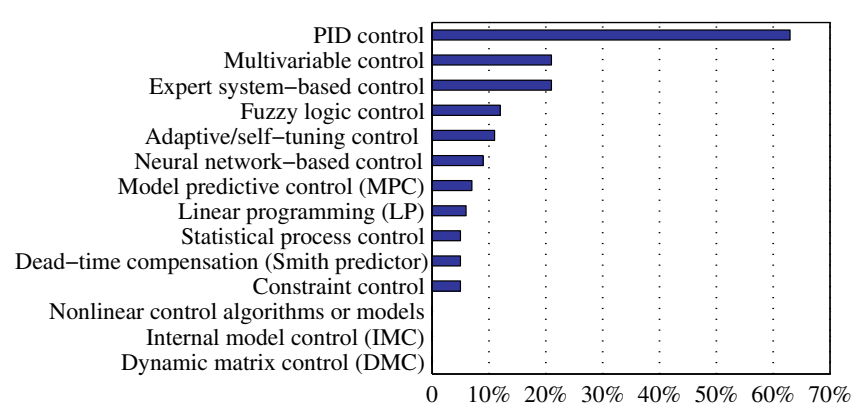

Fig. 10. Control technologies used in milling circuits.

$\left(0.39^{2}\right)$, using Eq. (9). Minimum variance control can therefore theoretically reduce the standard deviation by $90 \%$. Furthermore, with this minimum variance and the assumption that the controller works perfectly and the PSD operating point is $80 \%$, the best achievable average recovery (EPI) can be derived as $70.69 \%$ using Eq. (7), an improvement of $1.08 \%$ over the base case, and accordingly the value of the mineral recovered is $(70.69 k) \%$.

\section{Framework step 2: advanced controller design}

Step 2 is the design of the new control system, as seen in Fig. 1. Various control design technologies can be used here. In this section the control technologies used in grinding mill circuits are described briefly. NMPC, which is selected as the advanced controller, is described in Section 5.2.

\subsection{Control technologies used in milling circuits}

Control techniques used in grinding circuits are investigated in a survey study (Wei and Craig, 2009) and the results shown in Fig. 10. The majority of the respondents use PID control (63\%). Multivariable control and expert system-based control are used less frequently but more often than other control technologies.

In support of the survey results, it is stated in Edwards et al. (2002) that the most common controller is of the PID type, which is confirmed by Ivezić and Petrović (2003), who declare that more than half of all industrial milling circuit controllers are of the PID type. There are several reasons for the domination of PID controllers. Firstly they are relatively easy to understand and implement. Higher levels of skills, which are often in short supply for the installation and maintenance of advanced controllers, are not required for PID controllers. Another barrier to the commissioning of advanced control is that plants are often reluctant to permit advanced control vendors to monitor their processes remotely, which could offset the shortage of skilled manpower. PID control, as applied to grinding circuits, is discussed in Edwards et al. (2002), Flament et al. (1997), Desbiens et al. (1997a) and Pomerleau et al. (2000).

Multivariable control is discussed in Pomerleau et al. (2000), Hulbert et al. (1990) and Craig and Macleod (1996). Numerous applications have indicated that model-based expert system controllers are useful when performing optimized supervisory control of natively complicated mineral processes Samskog et al. (1996). Expert system-based control is discussed in Sotelo et al. (1997), Samskog et al. (1996) and Lo et al. (1996).

Fuzzy logic control is discussed in van Dyk et al. (2000) and adaptive control is investigated in Desbiens et al. (1997b). Neural network-based control is examined in Stange and McInnes (1995) and dead-time compensation is discussed in Anderson et al. (1996).

Model predictive control, which is the advanced control method of choice in process industries as a whole, is becoming increasingly 
popular for milling circuit control (Muller and de Vaal, 2000; Ramasamy et al., 2005; Chen et al., 2007; Coetzee and Craig, 2007). Model predictive control has shown better performance in terms of setpoint tracking and the rejection of load disturbances (Freeman et al., 1994). Muller and de Vaal (2000) realize a model predictive controller for a milling circuit through simulation and results indicate that the controller is successful in controlling the particle size and in maximizing throughput.

In this paper, a nonlinear model predictive controller is selected as the advanced controller in view of the aforementioned popularity. The design of the controller is summarised in the following.

\subsection{NMPC controller design}

The NMPC controller designed in Coetzee et al. (2008) is selected as the advanced controller. NMPC utilises a nonlinear plant model to predict the behaviour of the process and derive the optimal control laws in terms of a given objective function. NMPC arises from nonlinear optimal control over a time interval into the future $t \in\left[t_{k}, t_{k}+T\right]$. Only the first control move is implemented and a new measurement is obtained. The nonlinear optimal control is then recalculated for the new time interval $\left[t_{k+1}, t_{k+1}+T\right]$.

The nonlinear optimal control problem calculates a control law $u$ such that it minimises a scalar performance function:

$$
\begin{aligned}
& \min _{x, u} \phi_{c}(x, u) \\
& \text { s.t. } \quad \dot{x}(t)=f_{c}(x(t), u(t), \tilde{p}) \\
& \theta_{c}(x, u) \leqslant 0 \\
& t_{0} \triangleq 0, x_{0} \triangleq x\left(t_{0}\right) \\
& t_{f} \triangleq T, x_{f} \triangleq x\left(t_{f}\right), \psi\left(x_{f}\right)=0
\end{aligned}
$$

where $x: \mathbb{R} \rightarrow \mathbb{R}^{n_{x}}$ is the state trajectory, $u: \mathbb{R} \rightarrow \mathbb{R}^{n_{u}}$ is the control trajectory, $x(t) \in \mathbb{R}^{n_{x}}$ is the state vector, $\dot{x}(t) \in \mathbb{R}^{n_{x}}$ is the state sensitivity to time, $u(t) \in \mathbb{R}^{n_{u}}$ is the control vector, $x_{f} \in \mathbb{R}^{n_{x}}$ is the terminal state vector, $(x, u) \mapsto \phi_{c}(x, u)$ is a scalar performance function, $(x, u) \mapsto \theta_{c}(x, u)$ is the inequality constraints function, $\psi: \mathbb{R}^{n_{x}} \rightarrow \mathbb{R}$ is the terminal constraint function, $\tilde{p} \in \mathbb{R}^{n_{p}}$ is the nominal parameter vector and $f_{c}: \mathbb{R}^{n_{x}} \times \mathbb{R}^{n_{u}} \times \mathbb{R}^{n_{p}} \rightarrow \mathbb{R}^{n_{x}}$ is a vector of ordinary differential equations describing the dynamics of the plant.

The nonlinear optimal control problem is cast as a nonlinear parameter optimization problem (Hull, 1997), which requires a continuous system model to be discretized. The discretization is achieved by splitting the prediction horizon $[0, T]$ into $N$ discrete time intervals named nodes $t_{0} \triangleq 0<t_{1}<t_{2} \cdots<t_{k}<\cdots$ $<t_{N-1}<t_{N} \triangleq T$ with the sampling time of $\tau_{s} \triangleq t_{k+1}-t_{k}$. The function of time $x(\cdot)$ and $u(\cdot)$ are replaced by their values at the nodes $x_{k} \in \mathbb{R}^{n_{x}}$ and $u_{k} \in \mathbb{R}^{n_{u}}$ for $k=0, \ldots, N-1$. The nonlinear optimal control problem is then changed into a parameter optimization problem.

The control horizon and prediction horizon result from a tradeoff between controller performance and calculation time; for more information see Coetzee et al. (2008). The scalar performance function $\left(\phi_{c}\right)$ is quadratic, as is the objective function $F=x^{T} Q x+u^{T} R u$. The objective function is convex which makes it easier to solve the resulting optimization problem, and the functional form also allows for setpoint following and constraining the control actions; deviations from setpoint are penalized as are excessive control action movements. $Q$ and $R$ are diagonal weighting matrices that have an impact on the states and the controls, respectively. The LOAD is given highest priority in the weighting matrix $Q$, followed by the PSD and then the SLEV. IPOPT (Kawajir et al., 2006) is used to solve the large-scale sparse nonlinear optimization problem.

\subsection{Performance of NMPC}

The designed NMPC controller is used in a simulation to control the milling circuit under the same disturbance scenario used in Section 4.2. The results are given in Fig. 11 and the statistics given in Table 5. It can be seen that NMPC performs much better than PID controllers with respect to disturbance rejection. The average recovery (EPI) for one day operation for the NMPC controller can then be calculated, as done in Section 4.3 using Eq. (7), being $70.66 \%$. The relevant recovered mineral value is $70.66 \mathrm{k} \%$, using Eq. (8).

\section{Framework step 3: estimation of performance and initial economic assessment}

In step 3 of the framework, the functional performance of advanced control is estimated first and then it is translated into economic performance, which will be compared to the economic performance of the base case to see how much the improvement is and whether the advanced controller is worth commissioning. If the answer is negative, the procedure is to re-design the advanced controller. Otherwise, the controller will be commissioned.

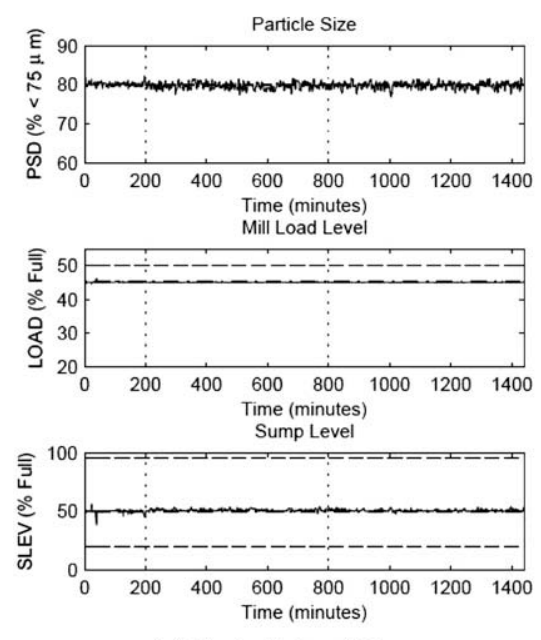

(a) Controlled variables
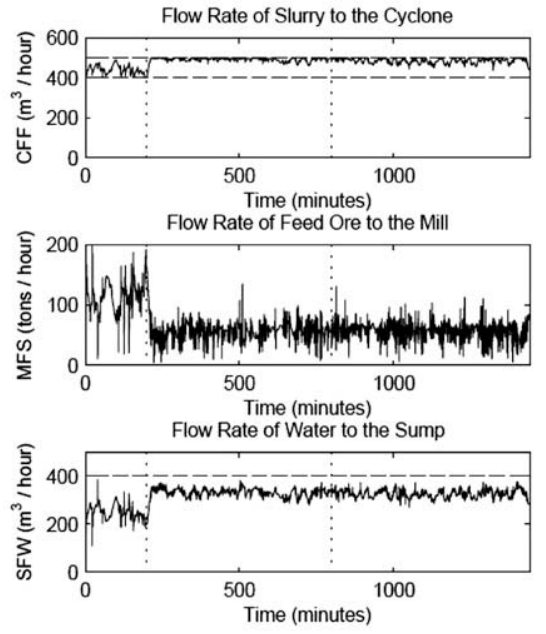

(b) Manipulated variables

Fig. 11. Controlled and manipulated variables of one day operation for the NMPC controllers. 
Table 5

Statistical data of controlled variables for the NMPC controller.

\begin{tabular}{lll}
\hline Controlled variable & $\mu_{y_{i}}$ & $\sigma_{y_{i}}$ \\
\hline PSD $(\%<75 \mu \mathrm{m})$ & 79.82 & 0.81 \\
LOAD $(\%$ full) & 44.99 & 0.07 \\
SLEV (\% full) & 50.77 & 1.06 \\
\hline
\end{tabular}

\subsection{Estimate APC performance}

In order to justify the investment in the implementation of the selected control technology, an estimate of the potential benefit that may result from the technology is required, as described in step 3 of the framework. In step 3, functional performance of the new controller needs to be estimated with two sub-objectives. The first is to estimate the reduction in the variance of process variables. The second is to determine the new setpoints for process variables with the new controller, which can be calculated based on the reduction in the variance and some optimization strategy (Latour, 1996; Bauer et al., 2007).

Estimating the performance of an advanced controller usually results in estimating the resulting reduction in the standard deviation of controlled variables. When the optimal operating point is near a constraint, which is often the case, the setpoint can be moved closer to the optimal point when the SD of a controlled variable is reduced. The reduction in variance is often assumed to be a fixed percentage. Reductions of 50\% and 35\% in the $\sigma$ are proposed in several publications (Latour, 1976; Latour, 1992; Martin et al., 1991; Martin, 2004). Some more optimistic estimates for the reduction are $85-90 \%$, as described in Latour et al. (1986) and Tolfo (1983).

Considering that the PID controller works well with respect to the LOAD and SLEV, the focus here is on the PSD. 50\% is selected as the estimate for the reduction in $\sigma$, i.e. the NMPC will reduce the $\sigma_{P S D}$ by $50 \%$ as compared to PID control (from 3.94 to 1.97 ). The operating point of the PSD for the NMPC controller is assumed as $80 \%$ owing to its inherent advantage in terms of disturbance rejection.

\subsection{Initial economic assessment of the two controllers}

In this section, the estimate of the EPI associated with the NMPC controller is undertaken by using the estimated operating point and $\sigma$ obtained in Section 6.1 and Eq. (7) to transfer functional performance into economic performance. The EPI of the new controller can then be compared to the EPI of the base case to judge whether there is a significant improvement in the system's economic performance. Using the minimum variance, the upper limit of the potential achievable performance improvement was derived in Section 4.4. The EPI of the new controller can also be compared to this upper limit to judge whether the improvement is satisfactory in terms of what can be achieved. If the EPI improvement is not acceptable, then the controller design of step 2 is repeated. Otherwise, the controller that was designed will be implemented.

It is assumed that the NMPC will perform no worse than the PID controllers in terms of LOAD and SLEV control, therefore, these two variables will remain within constraints. Based on the estimate that NMPC will reduce the PSD $\sigma$ by $50 \%$ at the operating point for the PSD of $80 \%$, the average recovery (EPI) for the mineral is derived as $70.65 \%$ using Eq. (7). The value of the mineral recovered is (70.65k)\% using Eq. (8), whereas the recovered mineral value of the base case is $(69.61 k) \%$. It can be seen that the recovered mineral value under NMPC control is (1.04k)\% more when compared to PID control. This may be an economically significant improvement, depending on the mineral processed.

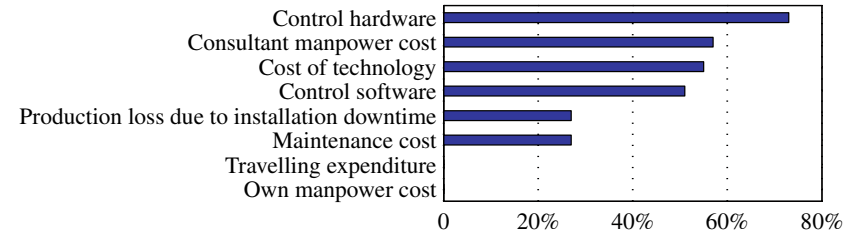

Fig. 12. Cost types of a process control system.

\section{Framework step 4: implementation of the advanced controller}

Assume now that the NMPC controller is implemented because of the significant potential recovery improvement. The main contributors to the costs of implementing a grinding control system are investigated in Wei and Craig (2009) and the results are shown in Fig. 12. The major contributors are control hardware, consultant manpower cost and the cost of the technology. These costs would form part of $\Delta C$ in Eq. (5). This is in contrast to results reported in Bauer and Craig (2008) for process industries as a whole, where manpower cost is dominant and control hardware plays a lesser role. In the next section, the advantage of the NMPC controller will be investigated further using a statistical experiment, as a simple PID/NMPC comparison is not sufficient (Craig and Koch, 2003).

\section{Framework step 5: calculation of performance and success assessment}

\subsection{Statistical comparison of two controllers}

In step 5 of the framework, the first task is to evaluate the functional performance of the new controller after implementation. It is convenient to do since the operating data are now available and the PDFs of the time series of the process variables can be derived.

\subsubsection{Motivation for the statistical experiment}

Although the results of Section 6.2 may indicate that some economic benefits resulting from improved control are possible, a single comparative test is not sufficient. It might happen that the experimental conditions favour NMPC, causing misleading results (Craig and Henning, 2000). The advanced controller might also have been tuned for a particular set of disturbances and it might not work well once other disturbances are introduced. In order to improve the accuracy of the comparison between the NMPC and PID controllers, a series of tests needs to be undertaken using experiment design techniques (Chatfield, 1983; Craig and Koch, 2003).

\subsubsection{Modelling of disturbances}

Feed ore hardness and composition changes are major disturbances that milling circuit controllers have to contend with. They are varied in the simulations described below to reflect typical operating conditions for the milling circuit being considered.

In particular, ore hardness and composition changes are modelled as both random and step disturbances. Hardness has a direct impact on the energy needed for grinding and ore composition refers to the rock fraction of the feed (Coetzee et al., 2008). Step disturbances simulate instances where e.g., the feed ore is switched between feeds that originate from different stockpiles. Uniform random disturbances are used to simulate natural variations in hardness and composition in the range $[-80 \% 80 \%]$ where zero is the nominal value. Stockpile segregation is modelled as a slow linear drift from a value of $36.4-53.2(\mathrm{kWh} / \mathrm{t})$ and from 0.15 to 0.04 (dimensionless) for hardness and rock fraction, respectively. 


\subsubsection{State the hypothesis}

For the purpose of this study, the performance of the PID and NMPC controlled milling circuits needs to be compared statistically. The LOAD and SLEV, controlled to stabilise the system, are controlled well and remain within the constraints for both cases. Hence, it is not necessary to compare these two variables statistically. The focus of the comparison is put on the PSD. The comparison of the mean PSD resulting from the PID and NMPC controllers can be related to a recovery difference that is economically meaningful. A trade-off relation between the quality (grind) and throughput exists for the milling circuit, as shown in Fig. 7 of Bauer and Craig (2008), i.e. the improvement in average grind will be at the expense of a decrease in average throughput. The significance of the PSD comparison is that, because of the characteristic of the $\mathrm{PF}$ of the PSD, the closer the operating point is to the setpoint, the better recovery will be achieved, which may cause significant economic improvements. The relevant null and alternative hypotheses are:

$$
\begin{aligned}
& H_{0}: \mu_{\mathrm{PSD}_{\mathrm{PID}}}=\mu_{\mathrm{PSD}_{\mathrm{NMPC}}} \\
& H_{1}: \mu_{\mathrm{PSD}_{\mathrm{PID}}}<\mu_{\mathrm{PSD}_{\mathrm{NMPC}}}
\end{aligned}
$$

The NMPC controller will then be regarded effective if $H_{0}$ can be rejected with a sufficient degree of significance. The experiment duration required to detect performance differences between two controllers depends on the degree of precision required, the amount of variability in the experimental material, and the available resources to conduct the experiment. In general, a higher significance level leads to a shorter experiment. As plant experiments are very expensive to conduct, and given the large variations in process variables that often occur relative to the change that the hypothesis test is testing for, the significance level is selected as $\alpha=0.15$ for the purpose of this experiment. See Craig and Koch (2003), for a more detailed explanation. It is also necessary to test whether there is a significant difference in the throughput rate (THR), which is also important practically. The null and alternative hypotheses are:

$$
\begin{aligned}
& H_{0}: \mu_{\mathrm{THR}_{\mathrm{PID}}}=\mu_{\mathrm{THR}_{\mathrm{NMPC}}} \\
& H_{1}: \mu_{\mathrm{THR}_{\mathrm{PID}}}>\mu_{\mathrm{THR}_{\mathrm{NMPC}}}
\end{aligned}
$$

The THR with the NMPC controller will then be regarded as statistically less than that for PID control if $H_{0}$ can be rejected with a sufficient degree of significance. The significance level is also selected as $\alpha=0.15$.

The recovery $(R)$ difference for the two controllers also needs to be statistically tested to see whether there is a considerable improvement. The null and alternative hypotheses are:

$$
\begin{aligned}
& H_{0}: \mu_{R_{\mathrm{PID}}}=\mu_{R_{\mathrm{NMPC}}} \\
& H_{1}: \mu_{R_{\mathrm{PID}}}<\mu_{R_{\mathrm{NMPC}}}
\end{aligned}
$$

Similarly, the recovery under NMPC will be regarded as significantly improved if $H_{0}$ can be rejected with a sufficient degree of significance. The significance level is also selected as $\alpha=0.15$.

\subsubsection{Experimental design}

Statistical techniques are available to assess the performance of processes operating under uncertainty. However, the use of these techniques in some process control industries is still relatively limited, compared to, e.g., the biological and social sciences (Craig and Koch, 2003). The performance of two controllers is regularly compared by simply switching between old and new controllers in a 'month-on, month-off' manner (Bauer and Craig, 2006). Plant improvement trials are therefore often inappropriately designed, and result in either no conclusion where a useful conclusion could be reached, or an incorrect conclusion (Napier-Munn, 1995).
Comparative experimental techniques can be classified approximately in terms of replication, blocking and randomisation (Chatfield, 1983). Most comparative experimental techniques take either one of these divisions or a combination of two or three.

In this study, a complete randomised design is used to perform the experiment. The disturbances of the hardness and composition vary over time and randomisation is used to ensure that the test data will be uncorrelated with these time trends. Blocking is not used, as the subdivision of the experiment into smaller time intervals will not reduce the variations of the data. If no considerable difference occurs, blocking will probably affect the accuracy of the experiment results adversely (Fisher and Yates, 1953). It is usually regarded as good practice to keep an experiment as simple as possible (Oosthuizen, 2001).

The selection of the duration for each test is based on the characteristics of the system and the test needs to be significantly longer than the longest time constant of the process. The duration is recommended to vary between one and three days in Craig and Henning (2000). In this study, one day is selected for the running period for each test, such that the milling circuit can reach steady-state under varying disturbances. The number of observations (in the form of simulations) is selected as 200 and each is $24 \mathrm{~h}$ long. A pseudo-random binary algorithm was used to determine which controller will be used when; the NMPC controller is used 103 times and the PID 97 times.

\subsubsection{Data generation and hypothesis testing}

8.1.5.1. Data generation. The simulations are conducted using the disturbances described in Section 8.1.2 and the experimental design described in Section 8.1.4. For the results of each day-long simulation, the average and $\sigma$ of the PSD, LOAD and SLEV are derived. The results of interest are summarised in Table 6 . The average PSD with the NMPC controller is improved by $4.62 \%$, compared to PID control. Note that the PSD setpoint for each controller is $80 \%$ passing $75 \mu \mathrm{m}$.

The $t$-test is used most commonly for comparative experiments. The two-sample $t$-test is used in this work, in which the means of the two sample sets are calculated and compared using standard statistical methods. The validity of the $t$-test is based on the following assumptions:

1. The data are distributed normally.

2. Each data point is a random independent sample of the population of all probable experimental results for the considered process.

3. The two sample variances are the estimates of the same population variance.

The first assumption is accepted a priori, which holds for most plants (Thornhill and Horch, 2007). The second assumption is also satisfied, as a complete randomised experiment design is used to ensure that the data samples are unrelated to the time trends of

\begin{tabular}{|c|c|c|c|c|c|}
\hline \multirow[t]{2}{*}{ Process variable } & \multirow[t]{2}{*}{ Setpoint } & \multicolumn{2}{|l|}{ Mean } & \multicolumn{2}{|l|}{$\sigma$} \\
\hline & & NMPC & PID & NMPC & PID \\
\hline PSD & $80(\%<75 \mu \mathrm{m})$ & 79.87 & 75.25 & 0.21 & 3.95 \\
\hline Throughput rate & & 71.88 & 72.55 & 4.87 & 5.24 \\
\hline Recovery & & 70.66 & 69.60 & 0.03 & 1.01 \\
\hline
\end{tabular}
disturbances. The third assumption needs be verified using an $F$ test, which investigates whether two standard deviations are significantly different.

Table 6

Summary of simulation results of statistical experiments. 
8.1.5.2. Hypothesis test on the PSD. As far as the PSD is concerned, the null hypothesis for the $F$-test is $H_{0 F}: s_{\mathrm{PID}}^{2}=s_{\mathrm{NMPC}}^{2}$. The alternative hypothesis is $H_{1 F}: s_{\mathrm{PID}}^{2}>s_{\mathrm{NMPC}}^{2}$. The $s_{\mathrm{PID}}^{2} / s_{\mathrm{NMPC}}^{2}$ follows an $F$ distribution with the degrees of freedom 96 and 102, whereas the sample size for PID and NMPC is 97 and 103, respectively. In order not to reject the $H_{0 F}$ with a significance level of 0.85 , the $s_{\mathrm{PIDj}}^{2} / s_{\mathrm{NMPC}}^{2}$ needs to be smaller than $F_{\text {inv }}(0.85,96,102)$, that is 1.23 . However, as the $s_{\mathrm{PID}}^{2} / s_{\mathrm{NMPC}}^{2}$ is 345.60 , the $H_{0 F}$ can then be rejected and the third assumption is not satisfied. The standard $t$-test can therefore not be used.

However, a robust t-test (Fisher and Yates, 1953) can be used, which can still provide valuable information. With this method, the population variance needs to be estimated based on the standard deviations of two samples, as given below:

$$
\begin{aligned}
s^{2} & =\frac{\left(n_{1}-1\right) s_{1}^{2}+\left(n_{2}-1\right) s_{2}^{2}}{n_{1}+n_{2}-2} \\
& =\frac{(97-1) 3.95^{2}+(103-1) 0.21^{2}}{97+103-2}=7.60
\end{aligned}
$$

where $n_{1}$ and $n_{2}$ are the sample size for the PID and NMPC control, respectively, and $s_{1}$ and $s_{2}$ are the standard deviations of the PSD for PID and NMPC control, respectively. The test statistic $t$ is derived as follows:

$t=\frac{\mu_{\mathrm{PSD}_{\mathrm{NMPC}}}-\mu_{\mathrm{PSD}_{\mathrm{PID}}}}{s \sqrt{1 / n_{1}+1 / n_{2}}}=\frac{79.87-75.25}{2.76 \sqrt{1 / 97+1 / 103}}=11.86$

The value of the statistic $t$ for the $85 \%$ confidence level with the degree of freedom 198 is 1.04 . $H_{0}$ can therefore be rejected with $85 \%$ confidence. The NMPC therefore provides better control statistically in respect of the PSD, the improvement being $4.62 \%$.

8.1.5.3. Hypothesis test on the throughput. The hypothesis test for the throughput rate is conducted, as for the PSD. The values of critical statistics are shown in Table 6. An F-test shows that the two throughput rate samples are from the same population, since the value of $s_{\mathrm{PID}}^{2} / s_{\mathrm{NMPC}}^{2}$ is 1.02 that is less than $F_{\text {inv }}(0.85,96,102)$ (1.23). Then a standard $t$-test is conducted. The statistic $t$ is

$t=\frac{\mu_{T_{H R_{P I D}}}-\mu_{T H R_{\mathrm{NMPC}}}}{\sqrt{\sigma_{1}^{2} / n_{1}+\sigma_{2} / n_{2}}}=\frac{72.55-71.88}{\sqrt{5.24^{2} / 97+4.87^{2} / 103}}=0.94$

Since the value of the $t$ is smaller than the $T_{i n v}(0.85,198)$ that is 1.04 , the null hypothesis can be accepted with significance level 0.15 . Then, it can be regarded that the throughput for PID controllers is the same as that for NMPC with 0.85 confidence. The hypothesis test for recovery and recovered mineral value in downstream flotation circuits will be conducted in Section 8.2, as it forms part of the economic assessment.

\subsection{Final EPA of the NMPC and PID controllers}

In this section the economic performance assessment of the PID and NMPC controllers is conducted based on the statistical experiment described in Section 8.1. In the experiment, the NMPC controller runs for 103 times and PID 97 times, with each run equalling $24 \mathrm{~h}$. Data of the controlled and manipulated variables are now available for each of the 200 runs. From the data the time series and PDF of the PSD can be obtained; further, based on the assumption of Gaussianity made above, the mean and standard deviation can be obtained. Based on the PF and the PDF of the PSD, the average mineral recovery in the downstream flotation circuit for each simulation is then derived using Eq. (7). Subsequently, the overall average mineral recovery for NMPC can be derived by averaging the 103 average recoveries for NMPC and 97 average recoveries for PID control. The value of the mineral recovered for a given time can then be obtained based on the overall average recovery and other parameters such as head grade, throughput rate and so on for either NMPC or PID control, using Eq. (1).

Note that it is not 'scientific' to obtain the overall average PSD and then to map the overall average PSD to the recovery, as this mapping only accounts for the mean information but neglects the role of the variation in the PSD. The mapping will lead to less accurate estimate of the system performance due to the oversimplification of the economic model (Martin et al., 1991).

\subsubsection{Hypothesis test on recovery}

The average recovery for the NMPC controller is $70.66 \%$ which is $1.06 \%$ bigger than the $69.60 \%$ achieved by the single-loop PID controllers. A hypothesis test is conducted to examine the statistical significance of the improvement, as conducted in Section 8.1.5. The standard deviation of the recovery is 0.03 and 1.01 for NMPC and PID, respectively. An F-test indicates that two recovery samples are not from the same population, since the value of $s_{\mathrm{PID}}^{2} / s_{\mathrm{NMPC}}^{2}$ is 1099.70 which is bigger than $F_{\text {inv }}(0.85,96,102)$ (1.23). A robust $t$-test is then used to examine whether the difference of recovery is statistically significant. The population variance is estimated as:

$$
\begin{aligned}
s^{2} & =\frac{\left(n_{1}-1\right) s_{1}^{2}+\left(n_{2}-1\right) s_{2}^{2}}{n_{1}+n_{2}-2} \\
& =\frac{(97-1) 1.01^{2}+(103-1) 0.03^{2}}{97+103-2}=0.49
\end{aligned}
$$

where $n_{1}$ and $n_{2}$ are the sample size for PID and NMPC control, respectively, and $s_{1}$ and $s_{2}$ are the standard deviations of the PSD for PID and NMPC control, respectively. The test statistic $t$ is derived as follows:

$t=\frac{\mu_{R_{\mathrm{MMPC}}}-\mu_{R_{\mathrm{PID}}}}{s \sqrt{1 / n_{1}+1 / n_{2}}}=\frac{70.66-69.60}{0.71 \sqrt{1 / 97+1 / 103}}=10.60$

The value of the statistic $t$ for the $85 \%$ confidence level with the degree of freedom 198 is 1.04 . $H_{0}$ can therefore be rejected with $85 \%$ confidence. The recovery for NMPC is therefore significantly bigger than that of the PID controllers.

\subsubsection{Hypothesis test for the value of recovered mineral in downstream flotation circuits}

The recovered mineral value can be calculated using Eq. (1), and here the head grade and mineral price are assumed to be the same for both controllers. Then the recovered mineral value depends on only the recovery and throughput rate, and a variable $\omega$ is defined as their product. The mean $\omega$ for NMPC is 5090.49 and for PID it is 5054.49. The null hypothesis is that both controllers result in recovering the same quantity of mineral. An F-test shows that the two samples of the recovered mineral value are from the same population, since the value of $s_{\mathrm{NMPC}}^{2} / s_{P I D}^{2}$ is 0.57 , which is less than $F_{\text {inv }}(0.85,96,102)(1.23)$, i.e. a standard $t$-test can be conducted. The statistic $t$ is

$t=\frac{\mu_{\omega_{\mathrm{NMPC}}}-\mu_{\omega_{\mathrm{PID}}}}{\sqrt{\sigma_{1}^{2} / n_{1}+\sigma_{2} / n_{2}}}=\frac{5090.49-5054.49}{\sqrt{227.24^{2} / 103+172.21^{2} / 97}}=1.27$

Since the value of $t$ is bigger than that of $T_{\text {inv }}(0.85,198)$ that is 1.04 , the null hypothesis can be rejected with significance level 0.15 . The recovered mineral value due to the NMPC controller is bigger than that for PID controllers with 0.85 confidence.

Furthermore, besides the recovered mineral value obtained above, other cost/profit factors can also influence economic performance, e.g., the reduction of energy consumption, the controller installation cost, the control software and hardware cost. Because 
of the limitation of simulation study, these elements are not considered further in this paper, but are significant in practice.

\section{Discussion}

Generally, owing to improved control, the setpoint of controlled variables can be moved to a more profitable operating point, and the benefit results from reducing the controlled variable variance and from moving operating point in a more profitable direction. The PID controllers in this paper cannot run the milling circuit at the same operating point as the NMPC controller does. This means that although the setpoint for both controllers is the same, they operate at different operating points, e.g., for the PSD in the statistical experiment, NMPC operates at 79.87 (passing $75 \mu \mathrm{m}$ ) and PID operates at 75.25 (passing $75 \mu \mathrm{m}$ ). The economic improvement of NMPC, compared to PID, therefore comprises two parts, namely the reduction of controlled variable variance and operating at a more profitable operating point.

It is interesting to examine by how much the improvement in recovery results from the variance reduction and the improvement in operating point, respectively. Taylor expansion can be used for this purpose (Chatfield, 1983). The average performance is related to the operating point, the variance of the time series of controlled variables and the characteristic of the relevant performance functions. The proof is given as is done for the performance function of concentrate grade in (Craig and Koch, 2003), from which it can be seen that:

$\bar{y}=f(\bar{x})+0+\frac{1}{2} f^{\prime \prime}(\bar{x}) s^{2}+\operatorname{Rem} \approx f(\bar{x})+\frac{1}{2} f^{\prime \prime}(\bar{x}) s^{2}$

For the PF of the PSD, as shown in Fig. 6, the first derivative is $2 a x+b$ and the second derivative is $2 a(-0.02)$ in the range of interest. Because the third and higher derivatives are all 0 , the Rem becomes 0 . Therefore

$\bar{y}=f(\bar{x})-0.01 s^{2}$

Note that the PID controllers run the circuit at $\bar{x}_{P I D}$ and NMPC at $\bar{x}_{\mathrm{NMPC}}$, and accordingly the standard deviations $s_{\mathrm{PID}}$ and $s_{\mathrm{NMPC}}$, respectively. Then

$\bar{y}_{\text {PID }}=f\left(\bar{x}_{\text {PID }}\right)-0.01 s_{\text {PID }}^{2}$

$\bar{y}_{\mathrm{NMPC}}=f\left(\bar{x}_{\mathrm{NMPC}}\right)-0.01 s_{\mathrm{NMPC}}^{2}$

Then there is

$\bar{y}_{\mathrm{NMPC}}-\bar{y}_{\mathrm{PID}}=\left[f\left(\bar{x}_{\mathrm{NMPC}}\right)-f\left(\bar{x}_{\mathrm{PID}}\right)\right]-0.01\left(s_{\mathrm{NMPC}}^{2}-s_{\mathrm{PID}}^{2}\right)$

It can be seen that the difference in average recovery depends on the operating point and variable variance. Furthermore, owing to the coefficient -0.01 (resulting from the small second derivative of the PF), the influence of the reduction of the controlled variable variance on average recovery is small in this case. The improvement in recovery therefore mainly results from the improvement in the operating point. If the operating point in two runs are the same, the average recovery will be very close. This result is of course heavily dependent on the characteristic of the PSD PF.

\section{Conclusions}

In this paper, an economic performance assessment for two ROM ore milling circuit controllers has been cast in a recently proposed framework for the economic evaluation of advanced control systems. Performance functions of the milling circuits, which play a key role in the assessment, were developed a priori.

The assessment indicated that the economic performance of NMPC is better than that of PID with respect to recovery and recovered mineral value in the downstream flotation circuit. The reason is that, because of significantly improved disturbance rejection, the NMPC controller can operate at an operating point closer to the setpoint. In addition, the reduced variance of PSD under NMPC can also contribute to economic improvement. However in this case the controlled variable variance reduction only contributes a small part of the economic improvement due to the shape of the PF used.

\section{Acknowledgements}

This work was sponsored by the National Research Foundation of South Africa and the University of Pretoria. Thanks to Jeremy Bosman for helping to discuss the performance functions of the milling circuit. Thanks also to Loutjie Coetzee for the help on the controllers used in the paper.

\section{References}

Anderson, L., Perry, R, Neale, AJ, 1996. Application of deadtime and gain compensation to SAG feeder control at P.T.F report Indonesia. In: Proceedings of the 28th Annual Meeting of the Canadian Mineral Processors. Paper no. 24, Ottawa, Ontario.

Bascur, O.A., 1991. Integrated grinding/flotation controls and management. In: Proceedings of the Copper 91-Cobre 91, vol. 2, pp. 411-427.

Bauer, M., Craig, I.K., Apr., 2006. Economic performance assessment of APC projects - a review and framework. In: Proceedings of the SICOP Workshop. Gramado, Brazil.

Bauer, M., Craig, I.K., 2008. Economic assessment of advanced process control - a survey and framework. Journal of Process Control 18 (1), 2-18.

Bauer, M., Craig, I.K., Tolsma, E., deBeer, H., 2007. A profit index for assessing the benefits of process control. Industrial and Engineering Chemistry Research 46, 5614-5623.

Bawden, N.M., 1993. The prediction, quantification and evaluation of advanced control benefits. Master's thesis, the University of Witwatersrand.

Bazin, C., Grant, R., Cooper, M., Tessier, R., 1994a. A method to predict metallurgical performances as a function of fineness of grind. Minerals Engineering 7 (10), 1243-1251.

Bazin, C., Grant, R., Cooper, M., Tessier, R., 1994b. The prediction of metallurgical performances as a function of fineness of grind. In: Proceedings of the 26th Annual Meeting of the Canadian Mineral Processors. Canadian Mineral Processors, Ottawa.

Bazin, C., Grant, R., Duchesne, S., 1995. Simulation of flotation bank performances as a function of fineness of grind. In: Proceedings of 19th International Mineral Processing Congress, vol. 3. p. 221.

Bourassa, M., Lanthier, R., Beaudoin, P., Chéfa, S., 1995. Grinding circuit control optimization at mine Doyon. In: Proceedings of the 27th Annual Meeting of the Canadian Mineral Processors. Canadian Mineral Processors, Ottawa, pp. 295310.

Brisk, M.L., 2004. Process control: potential benefits and wasted opportunities. In: Proceedings of the 5th Asian Control Conference, pp. 10-16.

Chatfield, C.C., 1983. Statistics for Technology, third ed. Chapman and Hall, London

Chen, X., Zhai, J., Li, S., Li, Q., 2007. Application of model predictive control in ball mill grinding circuit. Minerals Engineering 20 (11), 1099-1108.

Choudhury, M.A.A.S., Shah, S.L., Thornhill, N.F., 2004. Diagnosis of poor control-loop performance using higher-order statistics. Automatica 40, 1719-1728.

Coetzee, L.C., Craig, I.K., Kerrigan, E.C., 2008. Nonlinear model predictive control of a run-of-mine ore milling circuit. In: Proceedings of the 17th IFAC World Congress. Elsevier, Korea. pp. 10620-10625.

Coetzee, L.C., Craig, I.K., Kerrigan, E.C., 2009. Robust nonlinear model predictive control of a run-of-mine ore milling circuit. Accepted by IEEE Transactions on Control Systems Technology.

Coetzee, L.C., Craig, I.K., 2007. Robust MPC of a run-of-mine ore milling circuit. In: Proceedings of the 7th IFAC Symposium on Nonlinear Control Systems. Pretoria, South Africa, pp. 904-909.

Craig, I.K., Henning, R., 2000. Evaluation of advanced industrial control projects: a framework for determining economic benefits. Control Engineering Practice 8, 769-780.

Craig, I.K., Hulbert, D.G., Metzner, G., Moult, S.P., 1992. Optimized multivariable control of an industrial run-of-mine circuit. Journal of the South African Institute of Mining and Metallurgy 92, 169-176.

Craig, I.K., Koch, I., 2003. Experimental design for the economic performance evaluation of industrial controllers. Control Engineering Practice 11, 57-66.

Craig, I.K., Macleod, I.M., 1996. Robust controller design and implementation for a run-of-mine ore milling circuit. Control Engineering Practice 4 (1), 1-12.

Desbiens, A., Flament, F., Pomerleau, A., 1997a. Distributed control at the Kidd Creek grinding plant. Part II: implementation. CIM Bulletin 90, 145-150.

Desbiens, A., Najim, K., Pomerleau, A., Hodouin, D., 1997b. Adaptive control practical aspects and application to a grinding circuit. Optimal Control Applications and Methods 18, 29-47.

Edwards, R., Vien, A., 1999. Application of a model-based size recovery methodology. In: Hodouin, D., Bazin, C., Desbiens, A. (Eds.), Control and 
Optimisation in Minerals, Metals and Materials Processing. The Metallurgical Society of CIM, pp. 147-160.

Edwards, R., Vien, A., Perry, R., 2002. Strategies for the instrumentation and control of grinding circuits. In: Mular, A.L., Halbe, D.N., Barratt, D.J. (Eds.), Mineral Processing Plant Design, Practice, and Control. Society for Mining Metallurgy and Exploration, pp. 2130-2151.

Feng, D., Aldrich, C., 1999. Effect of particle size on flotation performance of complex sulphide ores. Minerals Engineering 12 (7), 721-731.

Fisher, R.A., Yates, F., 1953. Statistical Tables for Biological, Agricultural and Medical Research, fourth ed. Oliver and Boyd, Edinburgh.

Flament, F., Desbiens, A., del Villar, R., 1997. Distributed control at the Kidd Creek grinding plant. Part I: control strategy design. CIM Bulletin 90, 139-144.

Freeman, N., Keenan, W., Hancock, S., LePage, G., 1994. Grinding circuit control techniques and experiences. In: Proceedings of the 5th Mill Operators' Conference, pp. 193-200.

Friedmann, P.G., 2006. Automation and Control Systems Economics, second ed. The Instrumentation, Systems, and Automation Society.

Galán, O., Barton, G.W., Romagnoli, J.A., 2002. Robust control of a SAG mill. Powder Technology 124, 264-271.

Grant, R., Bazin, C., Cooper, M., 1991. Optimizing grind using size by size recovery analysis at Brunswick Mining. In: Malhotra, D., Klimpel, R.R., Mular, A.L. (Eds.), Evaluation and Optimization of Metallurgical Performance, SME/AIME, p. 329.

Harris, T., Boudreau, F., MacGregor, J.F., 1996. Performance assessment using of multivariable feedback controllers. Automatica 32, 1505-1518.

Herbst, J.A., Alba J, F., Pate, W.T., Oblad, A.E., 1988a. Optimal control of comminution operations. International Journal of Mineral Processing 22, 275-296.

Herbst, J.A., Hales, L.B., Pate, W.T., Sepulveda, J.E., 1989. Report on actual benefits arising from the application of expert systems in industrial semi-autogenous grinding circuits. In: Proceedings of the IFAC Symposium on Automation in Mining, Mineral and Metal Processing. Argentina, pp. 53-60.

Herbst, J.A., Rajamani, K., Miller, J.D., Lin, C.L., 1988b. Development of a multicomponent multisize liberation model. Minerals Engineering 1 (2), 97111.

Hodouin, D., Jämsä-Jounela, S.-L., Carvalho, M.T., Bergh, L., 2001. State of the art and challenges in mineral processing control. Control Engineering Practice 9, 9951005.

Huang, B., 2002. Minimum variance control and performance assessment of time variant processes. Journal of Process Control 12, 707-719.

Huang, B., Ding, S.X., Thornhill, N., 2005. Practical solutions to multivariate feedback control performance assessment problem: reduced a priori knowledge of interactor matrices. Journal of Process Control 15, 573-583.

Huang, B., Shah, S.L., 1999. Performance Assessment of Control Loops: Theory and Application. Springer, New York.

Hulbert, D.G., 1989. The state of the art in the control of milling circuits. In: Proceedings of the IFAC Symposium on Automation in Mining, Mineral and Metal Processing. Argentina, pp. 1-10.

Hulbert, D.G., 2002. Evaluation of the economic benefits of milling circuit control. In: Basenez, L., laPuenta, J.A.D., Camacho, E.F. (Eds.), Proceedings of the 15th IFAC Triennial World Congress. Elsevier Science Barcelona, Spain.

Hulbert, D.G., Craig, I.K., Coetzee, M.L., Tudor, D., 1990. Multivariable control of a run-of-mine milling circuit. Journal of the South African Institute of Mining and Metallurgy 90 (7), 173-181.

Hull, D.G., 1997. Conversion of optimal control problems into parameter optimization problems. Journal of Guidance, Control, and Dynamics 20 (11), 57-60.

Ivezić, D.D., Petrović, T.B., 2003. New approach to milling circuit control - robust inverse nyquist array design. International Journal of Mineral Processing 70, 171-182.

Jelali, M., 2006. An overview of control performance assessment technology and industrial applications. Control Engineering Practice 14 (5), 441-466.

Jones, J.A., Deister II., R.D., Hill, C.W., Barker, D.R., Crummis, P.B., 1991. Process control at the DOE run company. In: Proceedings of SME Plant Operator Symposium. Denver, Colorado.

Kawajir, Y., Laird, C., Wachter, A., 2006. Introduction to Ipopt: a tutorial for downloading, installing, and using ipopt. Tech. rep., Carnegie Mellon University.

King, R.P., 1979. A model for the quantitative estimation of mineral liberation by grinding. International Journal of Mineral Processing 6, 207-220.

Latour, P., 2006. Demise and keys to the rise of process control. Hydrocarbon Processing 85, 71-80.

Latour, P.L., 1992. Quantify quality control's intangible benefits. Hydrocarbon Processing 71, 61-68.

Latour, P.L., 1996. Process control: CLIFFTENT shows it's more profitable than expected. Hydrocarbon Processing 75, 75-80.

Latour, P.L., Sharpe, J.H., Delaney, M.C., 1986. Estimating benefits from advanced control. ISA Transactions 65, 13-21.

Latour, P.R., 1976. The hidden benefits from better process control. Advances in Instrumentation 55, 1-11.

Lo, Y.C., Oblad, A.E., Herbst, J.A., 1996. Cost reduction in grinding plants through process optimization and control. Minerals and Metallurgical Processing 8, 1921.

Lynch, A.J., 1981. Mineral and Coal Flotation Circuits: Their Simulation and Control. Elsevier Scientific Pub. Co., New York.

Lynch, A.J., Bush, P.D., 1977. Mineral Crushing and Grinding Circuits: Their Simulation, Optimization Design, and Control. Elsevier Scientific Pub. Co., New York
Martin, G.D., 2004. Understand control benefits estimates. Hydrocarbon Processing 83 (10), 43-46.

Martin, G.D., Turpin, L.E., Cline, R.P., 1991. Estimating control function benefits. Hydrocarbon Processing 70, 68-73.

Martin, P.G., 2005. Bottom-line Automation, second ed. ISA, pp. 17-52.

Mascio, R.D., Barton, G.W., 2001. The economic assessment of process control quality using a Taguchi-based method. Journal of Process Control 11, 81-88.

Muller, B., de Vaal, P.L., 2000. Development of a model predictive controller for milling circuit. Journal of the South African Institute of Mining and Metallurgy 100 (7), 449-453.

Muske, K.R., Finegan, C.S., 2002. Analysis of a class of statistical techniques for estimating the ecomonic benefit from improved process control. In: Proceedings of the AIChE Symposium Series 326, vol. 98, pp. 408-412.

Napier-Munn, T.J., 1995. Detecting performance improvements in trials with timevarying mineral processes - three case studies. Minerals Engineering 8 (8), 843858.

Oosthuizen, D.J., 2001. Economic evaluation and design of an electric arc furnace controller based on economic objectives. Master's thesis, University of Pretoria.

Oosthuizen, D.J., Craig, I.K., Pistorius, P.C., 2004. Economic evaluation and design of an electric arc furnace controller based on economic objectives. Control Engineering Practice 12, 253-265.

Pomerleau, A., Hodouin, D., Desbiens, A., Gagnon, E., 2000. A survey of grinding circuit control methods: From decentralized PID controllers to multivariable predictive controllers. Powder Technology 108, 103-115.

Qin, S.J., 1998. Control performance monitoring - a review and assessment Computers and Chemical Engineering 23, 173-186.

Radhakrishnan, V.R., 1999. Model based supervisory control of a ball mill grinding circuit. Journal of Process Control 9 (3), 195-211.

Ramasamy, M., Narayanan, S.S., Rao, C.D.P., 2005. Control of ball mill grinding circuit using model predictive control scheme. Journal of Process Control 15 (3) 273-283.

Samskog, P.O., Söderman, P., Storeng, U., Björkman, J., Guyot, O., Broussaud, A., 1996 Model-based control of autogenous and pebble mills at LKAB Kiruna KA2 concentrator (Sweden). In: Proceedings of the International Autogenous and Semiautogenous Grinding Technology 1996. Vancouver, Canada, pp. 599-616.

Seborg, D.E., Edgar, T.F., Mellichamp, D.A., 2004. Process Dynamics and Control, second ed. John Wiely and Sons.

Skogestad, S., 2003. Simple analytic rules for model reduction and PID controller tuning. Journal of Process Control 13 (4), 291-309.

Sosa-Blanco, C., Hodouin, D., Bazin, C., Lara-Valenzuela, C., Salazar, J., 1999. Integrated simulation of grinding and flotation application to a lead-silver ore. Minerals Engineering 12 (8), 949-967.

Sosa-Blanco, C., Hodouin, D., Bazin, C., Lara-Valenzuela, C., Salazar, J., 2000. Economic optimisation of a flotation plant through grinding circuit tuning. Minerals Engineering 13 (10-11), 999-1018.

Sotelo, R.R., Gordon, L.M., Jewart, C., 1997. Implementing advanced control on a copper ore grinding circuit. In: ISA TECH/EXPO Technology Update Conference Proceedings, vol. 1, pp. 157-165.

Stange, W., McInnes, C., 1995. The intelligent control of an ROM milling circuit. In: Proceedings of the IFAC Symposium on Automation in Mining, Mineral and Metal Processing. Sun City, South Africa, pp. 359-364.

Stanley, G.G., 1987. The Extractive Metallurgy of Gold in South Africa, vol. 1. South African Institute of Mining and Metallurgy, Johannesburg.

Stout, T.M., Cline, R.P., 1976. Control system justification. Instrumentation Technology 23, 51-58.

Tabachnick, B.G., Fidell, L.S., 2001. Using Multivariate Statistics. Allyn and Bacon.

Thornhill, N.F., Horch, A., 2007. Advances and new directions in plant-wide disturbance detection and diagnosis. Control Engineering Practice 15 (10), 1196-1206.

Tolfo, F., 1983. A methodology to estimate economic returns of advanced control projects. In: Proceedings of the American Control Conference, pp. 1141-1145.

Trahar, W.J., 1981. A rational interpretation of the role of particle size in flotation. International Journal of Mineral Processing 8, 289-327.

Trahar, W.J., Warren, L.J., 1976. The flotability of very fine particles - a review. International Journal of Mineral Processing 3, 103-131.

van Dyk, W., Stange, W., Derbyshire, J., Williams, H., 2000. Optimum control of the Leeudoorn semi-autogenous milling circuit. CIM Bulletin 93 (1043), 106-110.

Wei, D., Craig, I.K., 2009. Grinding mill circuits - a survey of control and economic concerns. International Journal of Mineral Processing 90, 56-66.

Wei, D., Craig, I.K., Bauer, M., 2007. Multivariate economic performance assessment of an MPC controlled electric arc furnace. ISA Transactions 46 (3), 429-436.

Williams, A.K., Rameshi, M., 1998. Real-time economic control. Hydrocarbon Processing 77 (9), 99-110.

Wills, B.A., Napier-Munn, T., 2006. Mineral Processing Technology: An Introduction to the Practical Aspects of Ore Treatment and Mineral Recovery. ButterworthHeinemann, Oxford.

Yahmedi, S., Pomerleau, A., Hodouin, D., 1998. Robust controllers for grinding circuit. In: Proceedings of the IFAC Symposium on Automation in Mining, Mineral and Metal Processing. Germany, pp. 129-135.

Zhou, Y., 2002. Optimization-based benefits analysis for process control systems Master's thesis, University of Alberta.

Zhou, Y., Forbes, J.F., 2003. Determining controller benefits via probabilistic optimization. International Journal of Adaptive Control and Signal Processing $17,553-568$. 